\title{
The influence of wind speed on surface layer stability and turbulent fluxes over southern Indian peninsula station
}

\author{
M N Patil*, R T Waghmare, T Dharmaraj, G R Chinthalu, \\ Devendraa Simgh and G S Meena \\ Indian Institute of Tropical Meteorology, Dr Homi Bhabha Road, Pashan, Pune 411 008, India. \\ ${ }^{*}$ Corresponding author. e-mail: patil@tropmet.res.in
}

Surface to atmosphere exchange has received much attention in numerical weather prediction models. This exchange is defined by turbulent parameters such as frictional velocity, drag coefficient and heat fluxes, which have to be derived experimentally from high-frequency observations. High-frequency measurements of wind speed, air temperature and water vapour mixing ratio (eddy covariance measurements), were made during the Integrated Ground Observation Campaign (IGOC) of Cloud Aerosol Interaction and Precipitation Enhancement Experiment (CAIPEEX) at Mahabubnagar, India $\left(16^{\circ} 44^{\prime} \mathrm{N}\right.$, $77^{\circ} 59^{\prime} \mathrm{E}$ ) in the south-west monsoon season. Using these observations, an attempt was made to investigate the behaviour of the turbulent parameters, mentioned above, with respect to wind speed. We found that the surface layer stability derived from the Monin-Obukhov length scale, is well depicted by the magnitude of wind speed, i.e., the atmospheric boundary layer was under unstable regime for wind speeds $>4 \mathrm{~m} \mathrm{~s}^{-1}$; under stable regime for wind speeds $<2 \mathrm{~m} \mathrm{~s}^{-1}$ and under neutral regime for wind speeds in the range of $2-3 \mathrm{~m} \mathrm{~s}^{-1}$. All the three stability regimes were mixed for wind speeds $3-4 \mathrm{~m} \mathrm{~s}^{-1}$. The drag coefficient shows scatter variation with wind speed in stable as well as unstable conditions.

\section{Introduction}

The subgrid-scale surface momentum transport plays an important role in the exchange between the atmosphere and the underlying surface (Zhu and Furst 2013). This exchange is often parameterized in terms of the surface mean wind speed via drag coefficient $\left(C_{D}\right)$, as $C_{D}$ is shown to be a function of wind speed, frictional velocity, surface layer stability and heat fluxes. In many large-scale weather prediction models, surface turbulent fluxes are estimated using empirical relations in which $C_{D}$ is involved. In these models, accurate representation of the surface fluxes of heat and momentum (which depends upon $C_{D}$ ) is an important pattern (Miller et al. 1992), because the spatial distribution of these fluxes affects cloud formation (Clark and
Arritt 1995), non-classical mesoscale phenomena and thunderstorm (Segal and Arritt 1992). Over the Indian subcontinental stations, the steep decrease of $C_{D}$ (Kusuma et al. 1996; Krishnan and Kunhikrishnan 2002) as well as unsystematic (scatter) variations (Kusuma et al. 1996; Patil 2006) with wind speed was observed for low winds. Over the land region of Asia $\left(20^{\circ} \mathrm{N}-10^{\circ} \mathrm{S}\right)$, the $C_{\mathrm{DN}}\left(C_{D}\right.$ under neutral stability conditions) was $\sim 27.7 \times$ $10^{-3}$, which is close to $C_{\mathrm{DN}}$ over South America $\left(C_{\mathrm{DN}}=26.6 \times 10^{-3}\right)$, but significantly higher than the regions of North America, Africa, Europe, Australia and the rest of Asia (Garratt 1977). A study by Miao and Ji (1996) shows larger $C_{D}$ magnitude over the rough land surface than over the sea surface and found significant differences in the three typical underlying surfaces (urban, grassland and

Keywords. Drag coefficient; frictional velocity; latent heat flux; sensible heat flux; stability; eddy covariance. 
Gobi desert). $C_{\mathrm{DN}}$ was found to increase with an increase in wind speed for winds ranging from 2$16 \mathrm{~m} \mathrm{~s}^{-1}$ over the coastal upwelling area of northern California (Enriquez and Friehe 1997). Also, $C_{D}$ under weak wind conditions is sensitive to the exact method of calculation and choice of averaging time, but the decrease of $C_{D}$ with wind speed occurs for all calculation methods (Mahrt et al. 2001). For weak wind speeds $\left(<3 \mathrm{~m} \mathrm{~s}^{-1}\right), C_{D}$ decreases with increase in wind speed, but later it appears nearly constant (Mahrt et al. 2001). Recently, it was found that the relationship between the turbulence and wind speeds cannot be universal because of the stratification influence and site-dependent non-stationarity in the weak-wind regime (Mahrt et al. 2015). The above disorganised pattern of $C_{D}$ with wind speed produces difficulties in using windbased $C_{D}$ parameterization in numerical weather prediction models. In the present study, we quantify the $C_{D}$ and surface turbulent fluxes of heat and momentum, under low wind speed conditions, over the rural site of southern peninsular India. An attempt has been made to establish the boundary layer stability regime with wind speeds.

\section{Experiment, observations and weather conditions}

During the south-west monsoon season of the year 2011, as a part of the Cloud Aerosol Interaction and Precipitation Enhancement Experiment (CAIPEEX) (Kulkarni et al. 2012), an Integrated Ground Observations Campaign (IGOC) was conducted over the station Mahabubnagar $\left(16^{\circ} 44^{\prime} \mathrm{N}\right.$, $77^{\circ} 59^{\prime} \mathrm{E}, 498 \mathrm{~m}$ asl) in the south region of India. The high frequency $(10 \mathrm{~Hz})$ measurements of wind, temperature and humidity at $6 \mathrm{~m}$ above ground level (AGL), were carried out using the eddy covariance (EC) system (Patil et al. 2014; Chowdhuri et al. 2015). The EC system consisted of a $\mathrm{CO}_{2} / \mathrm{H}_{2} \mathrm{O}$ open path gas analyser (Model LI-7500A by Licor Inc.) integrated with a 3D sonic anemometer (Model wind master Pro by Gill Instruments) and the observational station and platform is shown in figure 1. Since both the sensors were part of the EC system, and were integrated to single data logger (LICOR), there was no time-lag in measurement by both the sensors. The complete description of both the sensors is given in table 1. The EC observations from August 9-13, 2011, were considered in the analysis, as this period was free from precipitation events. The measurement by slow response sensors for air temperature, wind speed, relative humidity at $1,2,4$, 12 and $18 \mathrm{~m}$ AGL and surface air pressure were also carried out. The observational site was on the outskirts of Mahabubnagar city, at a distance of $\sim 10 \mathrm{~km}$, having rural characteristics.

The surface meteorological observations at $1 \mathrm{~m}$ AGL, for the period of 9-13 August 2011, for wind
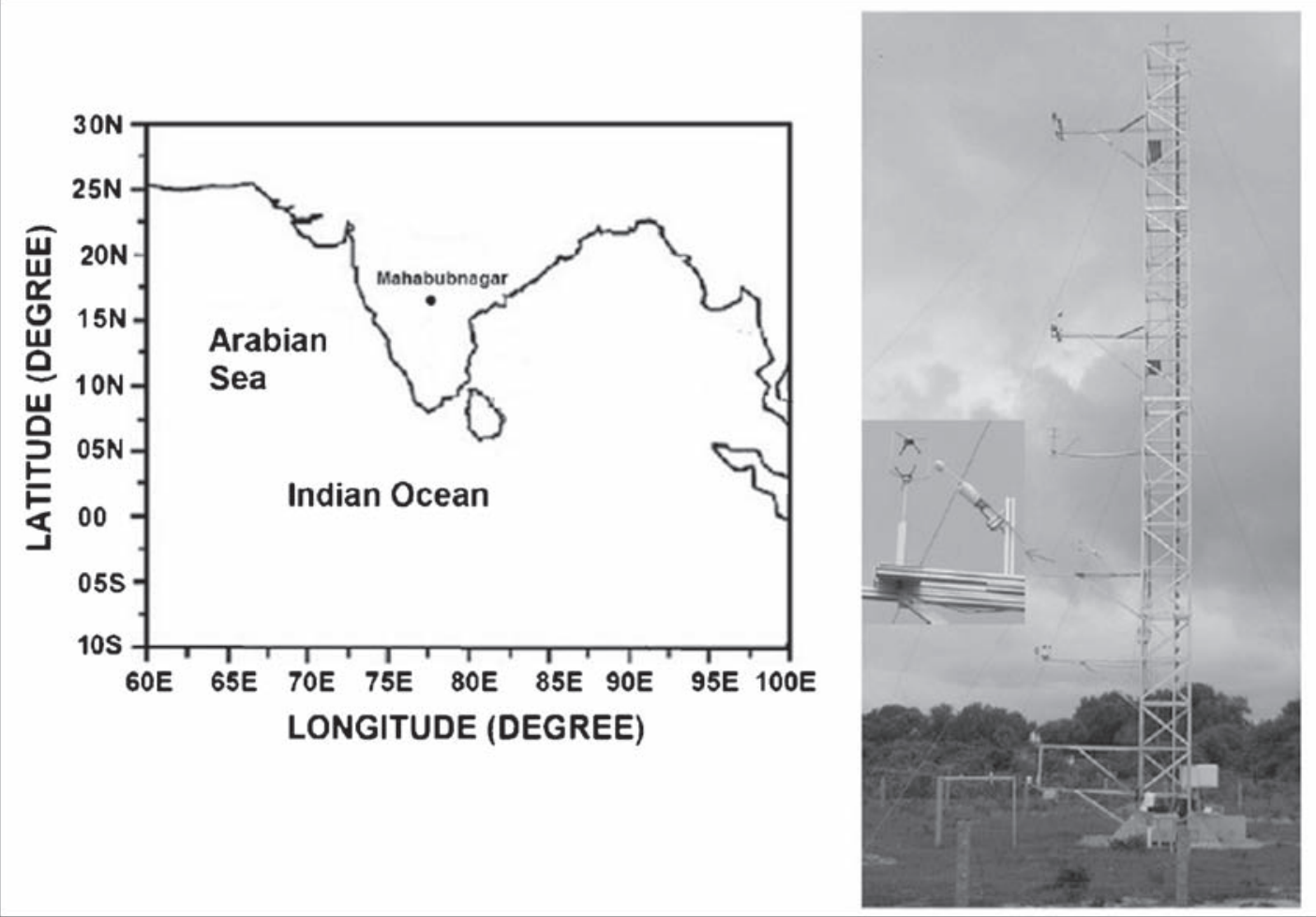

Figure 1. Observational site and measurement system used for collecting observations. 
Table 1. Specifications of the eddy covariance system installed during CAIPEEX-IGOC.

\begin{tabular}{|c|c|}
\hline $\mathrm{CO}_{2} / \mathrm{H}_{2} \mathrm{O}$ gas analyser - Model LI-7500A & 3D Sonic anemometer - Model WindPro \\
\hline Type & Outputs \\
\hline Absolute, open-path, non-dispersive infrared gas analysis & Output rate: $1,2,4,8,10,16,20,32 \mathrm{~Hz}$ \\
\hline Detector & Sample rate (automatically selected): 20 or $32 \mathrm{~Hz}$ \\
\hline Thermoelectrically cooled lead selenide & Units of measure: $\mathrm{m} / \mathrm{s}, \mathrm{mph}, \mathrm{KPH}, \mathrm{knots}, \mathrm{ft} / \mathrm{min}$ \\
\hline Output rate & Averaging: Flexible $0-3600 \mathrm{~s}$ \\
\hline \multicolumn{2}{|l|}{5,10 , or $20 \mathrm{~Hz}$, software selectable } \\
\hline Path length & Wind speed \\
\hline $12.5 \mathrm{~cm}$ & Range: $0-65 \mathrm{~m} \mathrm{~s}^{-1}$ \\
\hline Calibration range & Resolution: 0.01 or $0.001 \mathrm{~m} \mathrm{~s}^{-1}$ \\
\hline For $\mathrm{CO}_{2}: 0-3000 \mathrm{ppm}$ & Accuracy $\left(12 \mathrm{~m} \mathrm{~s}^{-1}\right)(\text { Standard })^{*}:<1.5 \%$ RMS \\
\hline For $\mathrm{H}_{2} \mathrm{O}: 0-60 \mathrm{ppt}$ & Accuracy $\left(12 \mathrm{~m} \mathrm{~s}^{-1}\right)$ (to special order $)^{*} \#:<1.0 \%$ \\
\hline Accuracy & RMS \\
\hline \multicolumn{2}{|l|}{ For $\mathrm{CO}_{2}$ : Within $1 \%$ of reading } \\
\hline For $\mathrm{H}_{2} \mathrm{O}$ : Within $2 \%$ of reading & Wind direction \\
\hline Zero drift $\left(\right.$ per $\left.{ }^{\circ} \mathrm{C}\right)$ & Range: 0-359.9 \\
\hline For $\mathrm{CO}_{2}: \pm 0.1$ ppm typical; \pm 0.3 ppm max. & Resolution: 1 or 0.1 \\
\hline \multirow[t]{7}{*}{ For $\mathrm{H}_{2} \mathrm{O}: \pm 0.03$ ppt typical; \pm 0.05 ppt max. } & Accuracy $\left(12 \mathrm{~m} \mathrm{~s}^{-1}\right)(\text { Standard })^{*}: 2$ \\
\hline & Accuracy $\left(12 \mathrm{~m} \mathrm{~s}^{-1}\right)$ (to special order) $)^{*} \#: 0.5$ \\
\hline & Speed of sound \\
\hline & Range: $300-370 \mathrm{~m} \mathrm{~s}^{-1}$ \\
\hline & Resolution: $0.01 \mathrm{~m} \mathrm{~s}^{-1}$ \\
\hline & Accuracy: $< \pm 0.5 \% @ 20^{\circ} \mathrm{C}$ \\
\hline & Sonic temperature range: $-40^{\circ} \mathrm{C}$ to $+70^{\circ} \mathrm{C}$ \\
\hline
\end{tabular}

speed, air temperature, relative humidity, and air pressure are shown in figure $2(\mathrm{a}-\mathrm{d})$. A moderate wind speed $\left(3-5 \mathrm{~m} \mathrm{~s}^{-1}\right)$ was observed in the afternoon hours. Sometimes, in the afternoon and evening hours, sudden fluctuations in air temperature of nearly $1^{\circ} \mathrm{C}$ were observed. Also, fluctuations in relative humidity were observed in the afternoon and evening hours. These fluctuations are due to the presence of non-precipitating clouds over the experimental station. The surface air pressure during the observational period was in the range of 950-957 mb. Figure 3 shows the diurnal variation of water vapour mixing ratio and virtual potential temperature $\left({ }^{\circ} \mathrm{C}\right)$ observed by the eddy covariance system over Mahabubnagar during 9-13 August, 2011. On the 10th and 11th August, there was an increase in water vapour in the afternoon and evening time. The virtual potential temperature was observed to be in the range of $28^{\circ}-34^{\circ} \mathrm{C}$, during the study period.

\section{Data analysis}

The observations collected at $10 \mathrm{~Hz}$ for $30-\mathrm{min}$ durations were stored in a single data file that consisted of 18,000 sample points. Each data file was processed separately. Instantaneous observations that have occasional spikes due to both electronic and physical noise were checked. If some spikes were detected, they were removed and the erroneous data points were replaced with the interpolated value of that observation. In all the available data files, very few files with few spikes were found. With the use of eddy covariance method, we computed the frictional velocity, sensible heat flux and latent heat flux. The natural wind coordinates were rotated for minimising the effect of vibrations and deviation of the sensors according to Lee et al. (2004). The WPL (Webb-Pearman-Leuning) correction for density effects due to heat and water vapour transfer (Webb et al. 1980) and data quality control test for steady state and integral turbulence characteristics (Foken and Wichura 1996) were adopted in the analysis.

Open-path analysers measure gas concentrations in situ, whereas traditional closed-path analysers draw air from above the canopy through an intake tube to an analyser housed at some distance from the sampling point. An open-path system has a relatively small spectral flux attenuation at high frequencies, but it can be considerably greater for closed-path systems. On the other hand, in closed-path systems, apparent flux magnitude arising from air density fluctuations is small because air temperature fluctuations are effectively damped during travel from the inlet location to the analyser. Heat or water vapour causes expansion of the air and thus affects the constituent's density. Therefore, open path analysers, which directly 

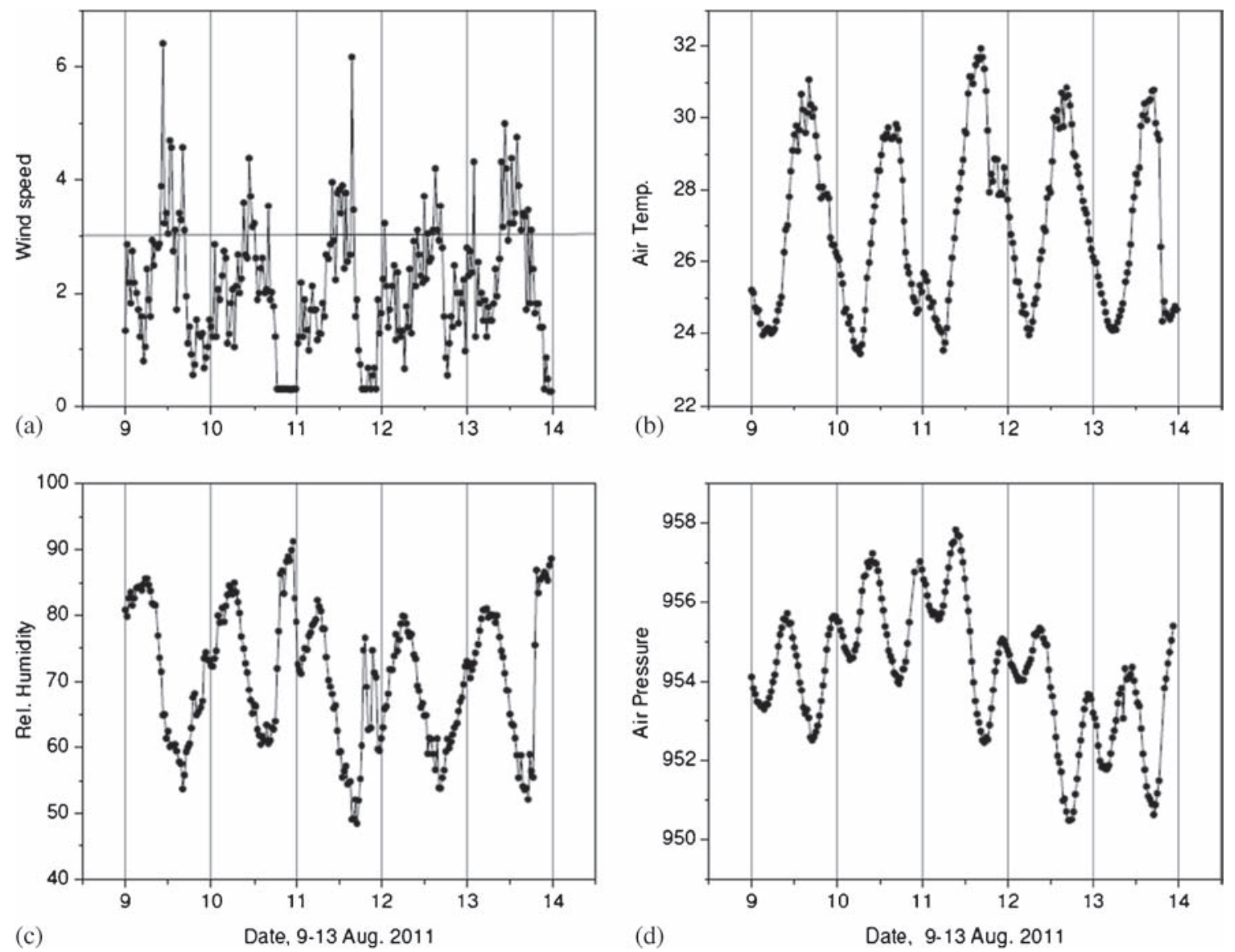

Figure 2. The surface meteorological conditions at $1 \mathrm{~m}$ above ground level that prevailed over Mahabubnagar during 9-13 August 2011, for (a) wind speed $\left(\mathrm{m} \mathrm{s}^{-1}\right)$, (b) air temperature $\left({ }^{\circ} \mathrm{C}\right)$, (c) relative humidity $(\%)$, and (d) surface air pressure (mb).
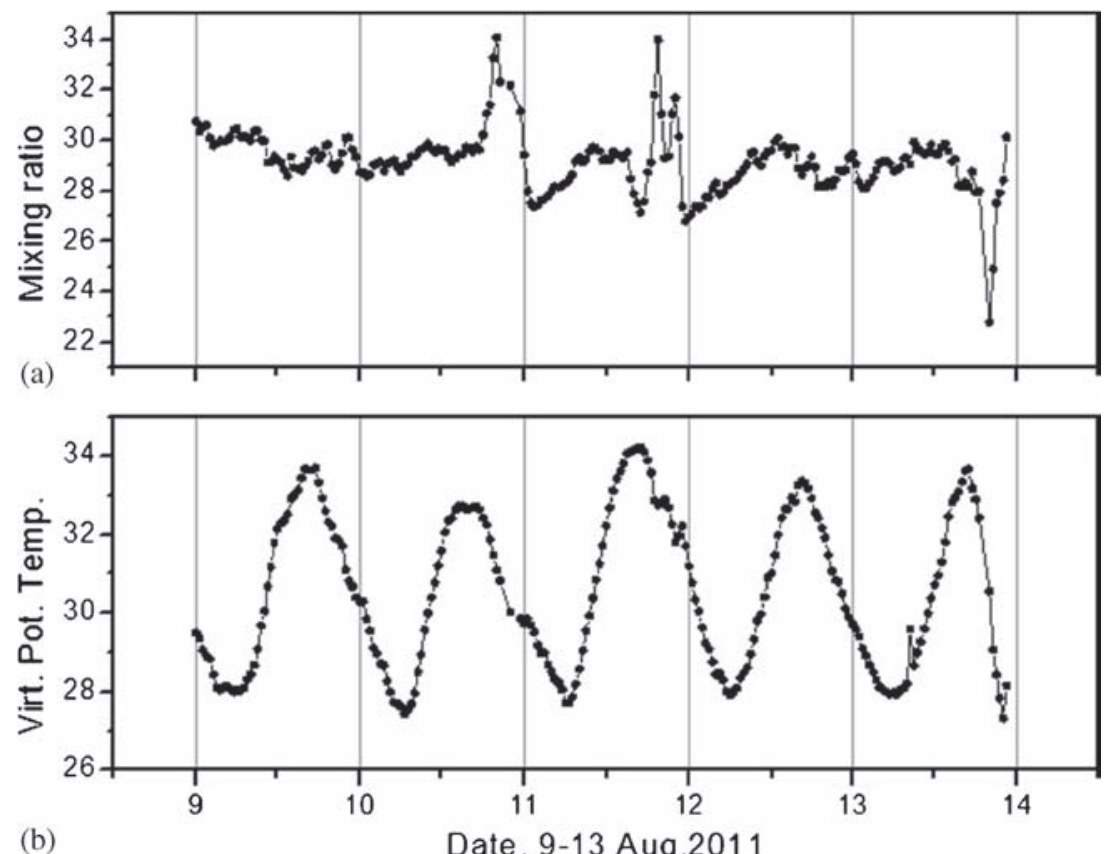

Figure 3. The diurnal variation of (a) water vapour mixing ratio in $\mathrm{g} \mathrm{kg}^{-1}$ and (b) virtual potential temperature $\left({ }^{\circ} \mathrm{C}\right)$ over Mahabubnagar during 9-13 August, 2011. 
measure the mass-density of $\mathrm{CO}_{2}$ and $\mathrm{H}_{2} \mathrm{O}$, can be affected largely by fluctuations in air density. Usually, its effect on latent heat flux does not exceed $5 \%$, but it can be as large as $50 \%$ in the magnitude of $\mathrm{CO}_{2}$ flux (Leuning et al. 1982; Liebethal and Foken 2003, 2004; Mauder and Foken 2006).

To evaluate the magnitude of the influence of mean vertical flow, Webb et al. (1980) assumed that the vertical flux due to dry air density fluctuation should be zero. Recent work suggested that air density change due to air pressure expansion should also be considered (Lee and Massman 2011), but as it will have a relatively small effect on air density (Webb et al. 1980), this error can be neglected. Thus, an air density effect may cause substantial underestimates of turbulent fluxes (Leuning and Moncrieff 1990; Massman
1991). To deal with this, a detailed derivation of air density correction, which is commonly referred as WPL corrections, can be found in Webb et al. (1980). Ham and Heilman (2003) experimentally validated the WPL correction to the measurement of $\mathrm{CO}_{2}$ and $\mathrm{H}_{2} \mathrm{O}$ fluxes by the open-path eddy covariance technique over a dry asphalt surface and concluded that the WPL correction term almost cancels the apparent downward flux term.

\section{Results and discussion}

\subsection{Drag coefficient, frictional velocity} and stability in low-moderate wind speed

Diurnal variations of surface layer turbulent parameters for the period 9-13 August, 2011, is shown in figure 4 . The boundary layer was unstable

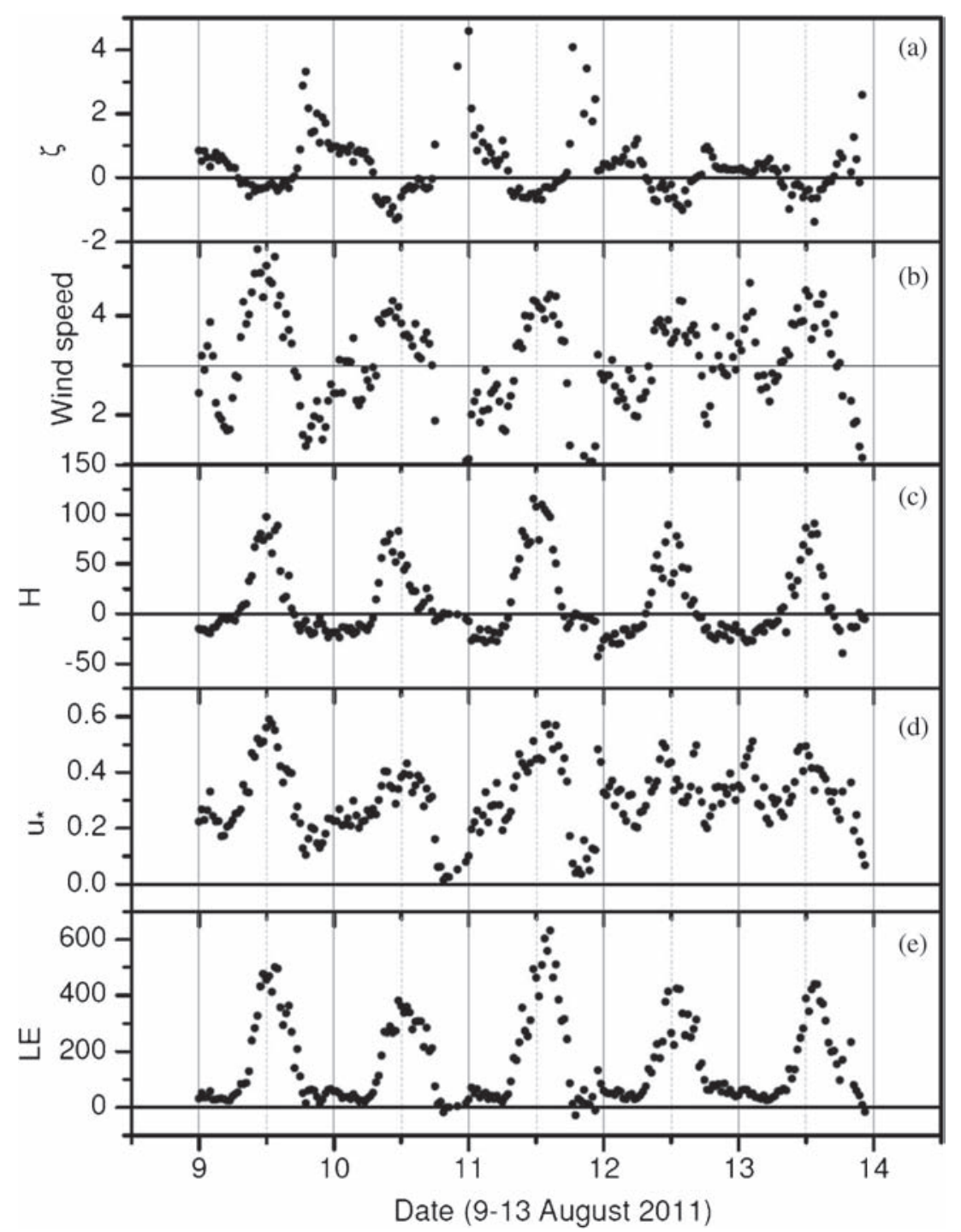

Figure 4. Diurnal variation of surface layer turbulent parameters from eddy covariance system for the period of 9-13 August 2011 (a) stability $-z / L$, (b) wind speed $\left(\mathrm{m} \mathrm{s}^{-1}\right)$, (c) sensible heat flux $\left(\mathrm{Wm}^{-2}\right)$ (d) frictional velocity (m $\left.\mathrm{s}^{-1}\right)$ and (e) latent heat flux $\left(\mathrm{Wm}^{-2}\right)$. 
with moderate wind speeds during daytime and it is stable with low wind speeds in the night-time. Similarly, fluxes of heat and frictional velocity were high in the daytime and attain low values during night-time.

For the discussion in this section, we divided all the turbulent parameters into two parts based on low $\left(<3 \mathrm{~m} \mathrm{~s}^{-1}\right)$ and moderate $\left(>3 \mathrm{~m} \mathrm{~s}^{-1}\right)$ wind speed conditions. The magnitude of $C_{D}$ was found to be in the range of $0.004-0.024$ and we did not find a systematic variation of $C_{D}$ with respect to wind speed (figure 5a, b). For the $C_{D}$ and wind speed relationship, the correlation coefficient was observed to be 0.08 for moderate winds and 0.24 for low winds indicating the absence of correlation. We also estimated the ' $p$-value' (the probability of obtaining a result) to measure the statistical significance of empirical analyses. These $p$-values

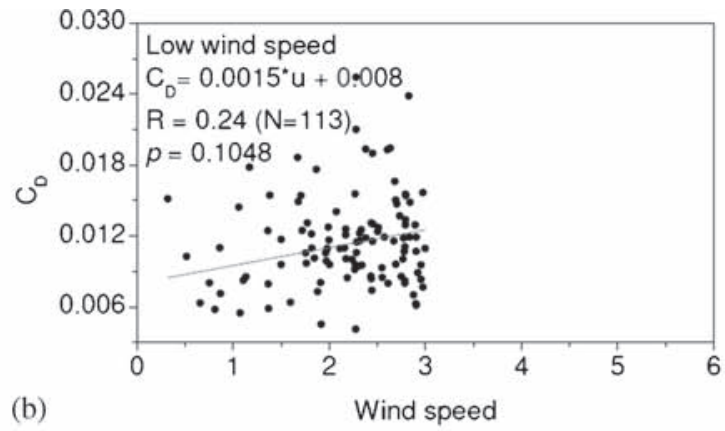

(a)

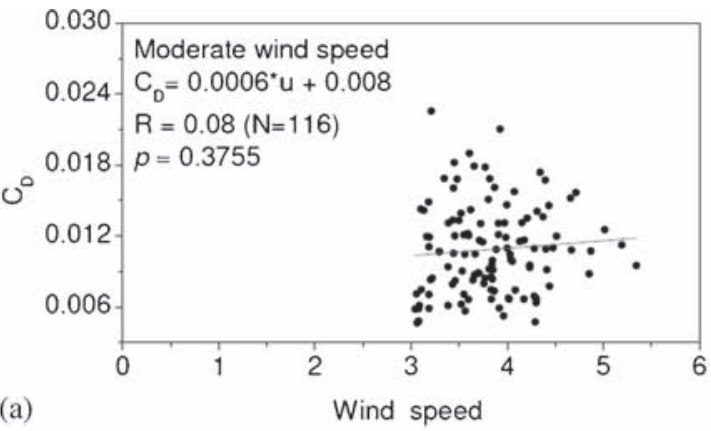

(b)

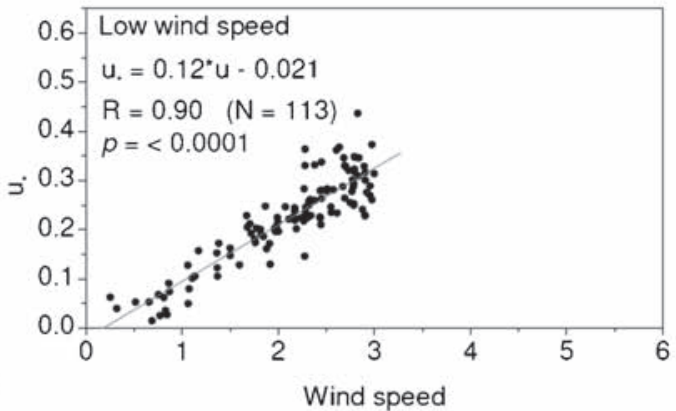

(c)

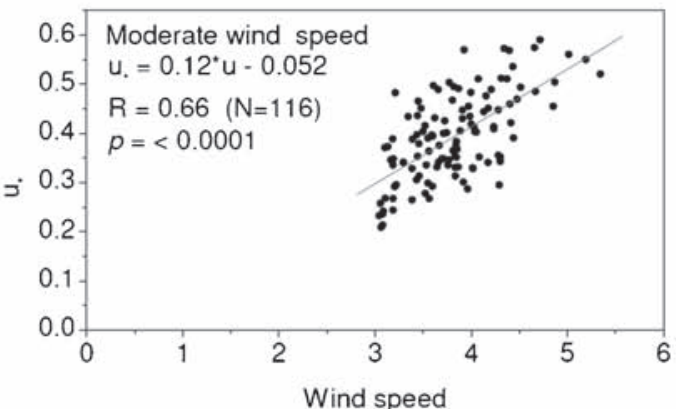

(d)

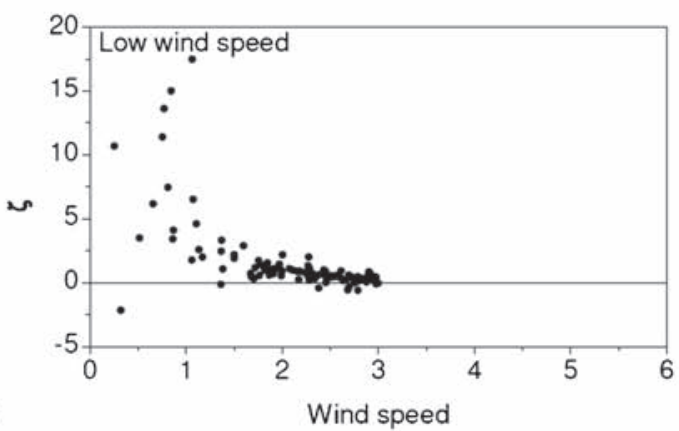

(e)

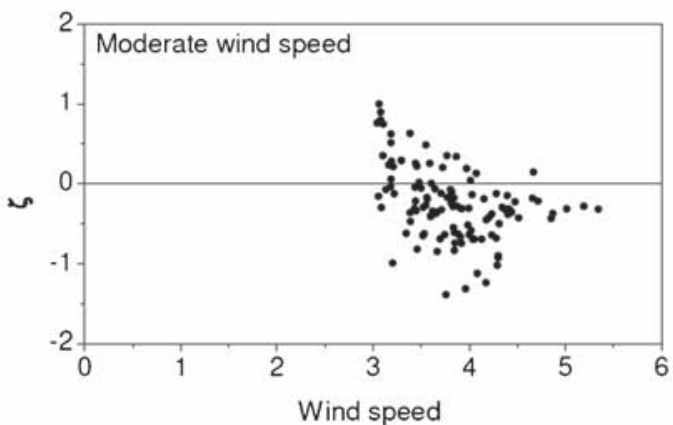

(f)

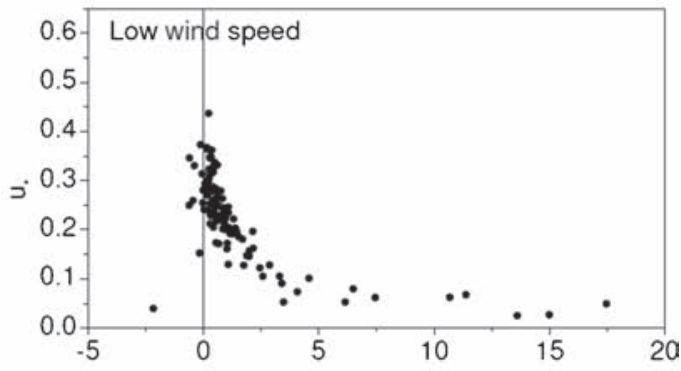

(h)

Figure 5. Variation of $C_{D}$ with wind speed (a) for wind speed $>3 \mathrm{~m} \mathrm{~s}^{-1}$, (b) for wind speed $<3 \mathrm{~m} \mathrm{~s}^{-1}$; variation of $u_{*}$ with wind speed, (c) for wind speed $>3 \mathrm{~m} \mathrm{~s}^{-1}$, (d) for wind speed $<3 \mathrm{~m} \mathrm{~s}^{-1}$; variation of $\zeta$ with wind speed, (e) for wind speed $>3 \mathrm{~m} \mathrm{~s}^{-1}$, (f) for wind speed $<3 \mathrm{~m} \mathrm{~s}^{-1}$; variation of $u_{*}$ with $\zeta$, (g) for wind speed $>3 \mathrm{~m} \mathrm{~s}^{-1}$, and (h) for wind speed $<3 \mathrm{~m} \mathrm{~s}^{-1}$. 
are given in the respective panel of the figure. For the $C_{D}$ and wind speed relationship, the $p$-value was observed to be 0.3755 for moderate winds and 0.1048 for low winds, indicating the relation is not statistically significant. However, in general, frictional velocity increases with increasing wind speed (figure 5c, d). The correlation between the linear increase of friction velocity with the increase in wind speed was stronger $(R=0.90)$ in weak winds than in moderate winds $(R=0.66)$. Also, for the wind and frictional velocity relation, the $p$-value for moderate and weak winds was $<0.0001$, indicating that the relation is highly statistically significant. Table 2 shows the mean of turbulent parameters derived for $0.25 \mathrm{~m} \mathrm{~s}^{-1}$ wind speed interval. It is seen that the frictional velocity increases with increase in wind speed. The vertical velocity was positive for wind speeds ranging from 1 to $4 \mathrm{~m} \mathrm{~s}^{-1}$. Similarly, the sensible heat flux was upward (positive) for wind speeds greater than $3.5 \mathrm{~m} \mathrm{~s}^{-1}$ and downward (negative) for wind speeds $<3 \mathrm{~m} \mathrm{~s}^{-1}$. The latent heat flux was always positive, and increasing its magnitude with respect to increasing wind speed. It is also seen in table 2 that $C_{D}$ does not show increasing or decreasing trend with respect to wind speed. The surface layer was stable for wind speeds $<3.50 \mathrm{~m} \mathrm{~s}^{-1}$ and it became unstable for wind speeds $>3.50 \mathrm{~m} \mathrm{~s}^{-1}$.

For wind speeds greater than $4 \mathrm{~m} \mathrm{~s}^{-1}$, the atmospheric boundary layer was unstable, as shown in figure $5(\mathrm{e})$. On the contrary, the boundary layer was stable for wind speeds less than 2 $\mathrm{m} \mathrm{s}^{-1}$ and near neutral condition for wind speeds ranging from $2-3 \mathrm{~m} \mathrm{~s}^{-1}$, as shown in figure $5(\mathrm{f})$. Both, stable as well as unstable conditions, were observed at wind speeds $3-4 \mathrm{~m} \mathrm{~s}^{-1}$. The frictional velocity was always greater than $0.2 \mathrm{~m} \mathrm{~s}^{-1}$ for the higher wind speed regime (figure $5 \mathrm{c}$ ). In the moderate wind speed regime (figure $5 \mathrm{~g}$ ), the frictional velocity was found to decrease with increasing stability $(\zeta=0.1-0.95)$. In low wind speed regime, the frictional velocity decreased with increase in stability up to $\zeta=4$ (figure $5 \mathrm{~h}$ ). For higher stable conditions, however, the frictional velocity was less than $0.1 \mathrm{~m} \mathrm{~s}^{-1}$. The observed unstable conditions could be due to high wind speeds associated with daytime boundary layer convections.

It is observed that, in some of the regional studies with low wind speed conditions, $C_{D}$ decreases with increase in wind speed in both, the mid-latitudinal (Mahrt et al. 2001; Xiao et al. 2013) as well as in the tropical (Kusuma et al. 1996; Krishnan and Kunhikrishnan 2002) regions. Also, an unsystematic (scatter) variation of $C_{D}$ with wind speed has been reported from tropical (Kusuma et al. 1996; Patil 2006) and mid-latitudinal (Wen et al. 2005; Suzuki et al. 2014) regions. These variations, which is either systematic or unsystematic, appear to be site specific as every site is characterised by different soil and vegetation properties and other regional climatic factors. Earlier, it was found that $C_{D}$ shows inconsistent behaviour with respect to different plant species in terms of its magnitude as well as stability (Gillies et al. 2002). Also, large variability (0.01-0.700) in the magnitude of $C_{D}$ was observed by Kusuma (2004) over the Indian site of Jodhpur for wind speeds less than $4 \mathrm{~m} \mathrm{~s}^{-1}$ under south-west monsoon conditions; however, the high values of $C_{D}$ were for the wind speeds less than $0.5 \mathrm{~m} \mathrm{~s}^{-1}$. For the strong wind conditions, over the coastal station near Galveston, Texas, $C_{D}$ was found to increase with an increase in wind speed for speeds ranging from 9 to $22 \mathrm{~m} \mathrm{~s}^{-1}$ (Zachry et al. 2013).

\subsection{Drag coefficient, frictional velocity and wind speed in different stability conditions}

For the discussion in this section, we divided all the turbulent parameters in stable $(\zeta>0)$ and unstable

Table 2. The observed mean of the turbulent parameters with respect to variable wind speed range.

\begin{tabular}{|c|c|c|c|c|c|c|c|c|}
\hline $\begin{array}{l}U \text { range } \\
\left(\mathrm{m} \mathrm{s}^{-1}\right)\end{array}$ & $U\left(\mathrm{~m} \mathrm{~s}^{-1}\right)$ & $u_{*}\left(\mathrm{~m} \mathrm{~s}^{-1}\right)$ & $w\left(\mathrm{~m} \mathrm{~s}^{-1}\right)$ & $H\left(\mathrm{~W} \mathrm{~m}^{-2}\right)$ & $L E\left(\mathrm{~W} \mathrm{~m}^{-2}\right)$ & $C_{D}$ & $\zeta$ & $N$ \\
\hline $0.26-0.75$ & 0.49 & 0.04 & $-1.18 \times 10^{-16}$ & -1.2 & 2.3 & 0.0182 & 6.8 & 5 \\
\hline $0.76-1.25$ & 0.95 & 0.08 & $+1.25 \times 10^{-16}$ & -4.6 & 16.1 & 0.0071 & 9.4 & 13 \\
\hline $1.26-1.75$ & 1.53 & 0.17 & $+4.81 \times 10^{-17}$ & -8.8 & 34.4 & 0.0119 & 1.5 & 11 \\
\hline $1.76-2.25$ & 2.00 & 0.20 & $+3.01 \times 0^{-17}$ & -14.2 & 50.4 & 0.0108 & 1.0 & 24 \\
\hline $2.26-2.75$ & 2.46 & 0.27 & $+1.66 \times 10^{-16}$ & -13.9 & 65.3 & 0.0125 & 0.5 & 38 \\
\hline $2.76-3.25$ & 2.98 & 0.30 & $+3.22 \times 10^{-16}$ & -11.0 & 90.8 & 0.0106 & 0.3 & 43 \\
\hline $3.26-3.75$ & 3.53 & 0.37 & $+1.62 \times 10^{-16}$ & 21.5 & 232.0 & 0.0114 & -0.2 & 36 \\
\hline $3.76-4.25$ & 3.96 & 0.41 & $+1.33 \times 10^{-16}$ & 45.6 & 275.8 & 0.0108 & -0.4 & 39 \\
\hline $4.26-4.75$ & 4.42 & 0.47 & $-5.56 \times 10^{-18}$ & 61.9 & 381.4 & 0.0114 & -0.4 & 18 \\
\hline $4.76-5.25$ & 4.98 & 0.52 & $+2.73 \times 10^{-16}$ & 82.3 & 417.6 & 0.0108 & -0.4 & 4 \\
\hline
\end{tabular}

Note: $U$ is the wind speed, $u_{*}$ is the frictional velocity, $w$ is the vertical velocity, $H$ is the sensible heat flux, $L E$ is the latent heat flux, $C_{D}$ is the drag coefficient, $\zeta$ is the $z / L$, where $z$ is the observational height and $L$ the Monin-Obukhov length, and $N$ is the number of samples. 
$(\zeta<0)$ conditions (figure 6$)$. The $C_{D}$ does not show any systematic variation with wind speed either in stable or in unstable conditions (figure 6a, b). For the drag coefficient and wind speed relationship, the correlation coefficient was observed to be -0.11 for the unstable case, and 0.14 for the stable case, indicating absence of correlation.
For $C_{D}$ and wind speed relationship, the $p$-value was observed to be 0.3059 for unstable and 0.1117 for stable conditions indicating that the relation is not statistically significant. However, the frictional velocity increases with increase in wind speed and shows a good linear relationship (figure 6c, d) with a correlation of 0.74 , under unstable, and 0.88 ,
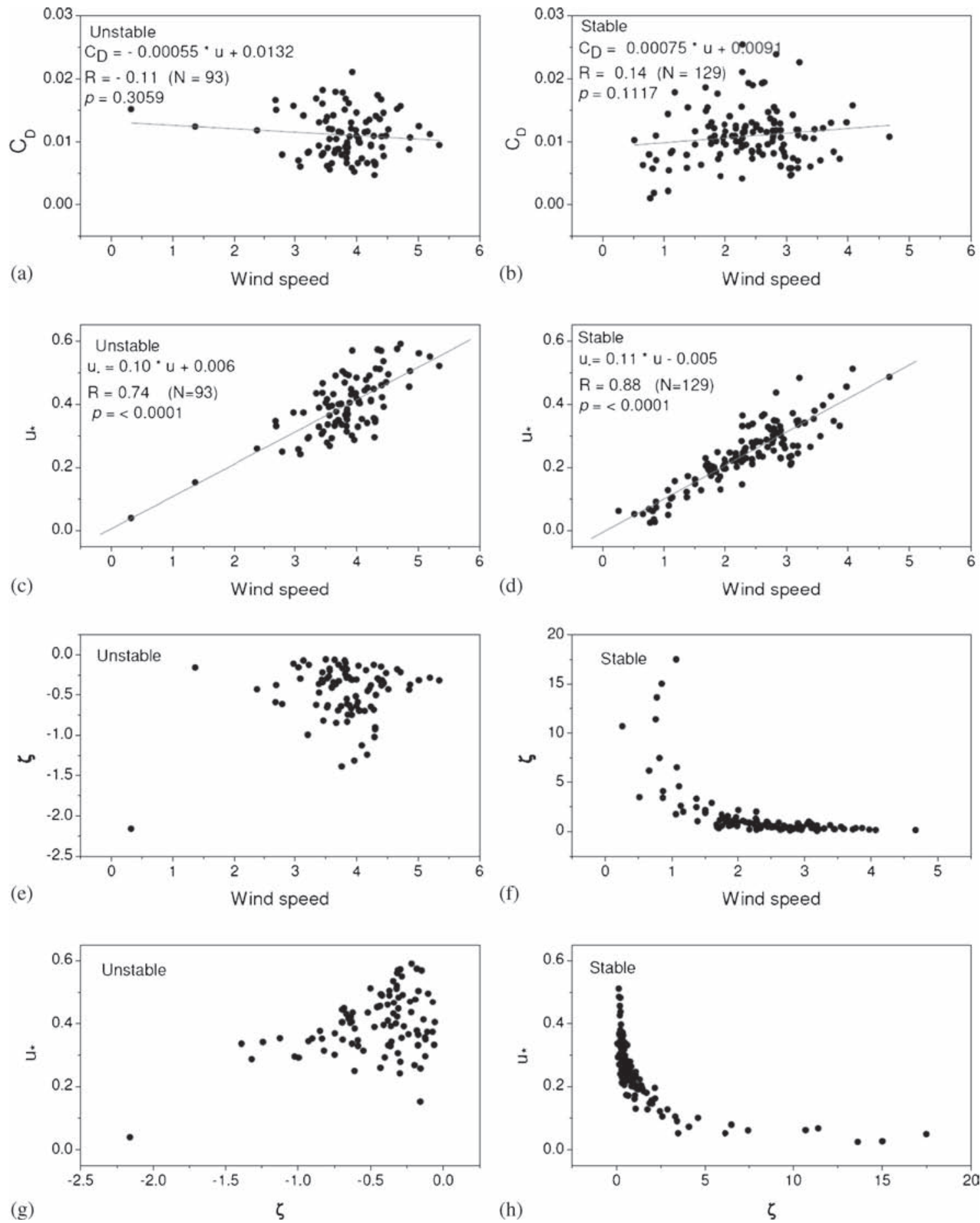

Figure 6. Variation of $C_{D}$ with wind speed (a) unstable conditions, (b) under stable conditions; variation of $u_{*}$ with wind speed, (c) unstable conditions, (d) under stable conditions; variation of $\zeta$ with wind speed, (e) unstable conditions, (f) under stable conditions; variation of $u_{*}$ with $\zeta$, (g) unstable conditions and (h) under stable conditions. 
under stable conditions. Also, for the wind and frictional velocity relation, the $p$-values for unstable as well as stable conditions were $<0.0001$ indicating that the relation is highly statistically significant. Also, it is observed that in most of the cases, unstable conditions were recorded for wind speeds $>3 \mathrm{~m} \mathrm{~s}^{-1}$ (figure 6e) and high stable conditions for wind speeds $<1.5 \mathrm{~m} \mathrm{~s}^{-1}$ (figure $6 \mathrm{f}$ ). The frictional velocity was greater than $0.2 \mathrm{~m} \mathrm{~s}^{-1}$ in most of the cases in unstable conditions (figure $6 \mathrm{~g}$ ) and it was nearly constant $\left(u_{*}=0.1 \mathrm{~m} \mathrm{~s}^{-1}\right)$ for highly stable conditions $(\zeta>5)$ as shown in figure $6(\mathrm{~h})$. In an earlier study (Agarwal et al. 1995), over the tropical site of Delhi, India, wind speeds of $<1 \mathrm{~m} \mathrm{~s}^{-1}$ were characterised with stable conditions and frictional velocity ranging from 0.01 to $0.11 \mathrm{~m} \mathrm{~s}^{-1}$; both, stable as well as unstable conditions, occurred at wind speed ranging from 1.07 to $3.48 \mathrm{~m} \mathrm{~s}^{-1}$, and the frictional velocity was ranging from 0.24 to $0.62 \mathrm{~m} \mathrm{~s}^{-1}$. The larger values of $C_{D}$ were reported for unstable conditions ( $\zeta$ ranging from -0.5 to 0 ) and $C_{D}$ under neutral stability, was 0.0205 and 0.0174 for south-west monsoon and winter conditions, respectively (Patil 2006). These magnitudes are consistent with the magnitude reported in this study. Table 3 shows the mean of turbulent parameters determined for the different $\zeta$ ranges. For neutral stability $(\zeta$ ranging from -0.05 to +0.05 ), the sensible and latent heat flux was 0.6 and $210.1 \mathrm{Wm}^{-2}$ respectively. $C_{D}$ appears to be highest at slightly stable case $(\zeta$ ranging from 0 to 0.25 ). As seen in table 3 , stability is well defined by the magnitude of wind speed. The surface layer appears to be more stable at low wind speeds; neutral at wind speed equal to $3.20 \mathrm{~m} \mathrm{~s}^{-1}$ and moderately unstable for higher wind speeds.

\subsection{Variation of sensible and latent heat fluxes with frictional velocity and stability}

Figure $7(\mathrm{a}$ and $\mathrm{b})$ shows the variation of sensible and latent heat flux with frictional velocity. The heat fluxes were higher for greater friction velocities. Similarly as shown in figure 7 (c and d), these fluxes were larger in unstable conditions. Under stable conditions, the sensible heat is in downward ( - ve) direction, but the latent heat flux was in upward (+ve) direction. However, the values of latent heat flux are reduced greatly in stable condition. Under neutral conditions $(\zeta \sim 0)$, sensible heat flux was observed between -3 and $5 \mathrm{Wm}^{-2}$, but latent heat flux was ranging between 55 and $315 \mathrm{Wm}^{-2}$. As shown in figure 7 (a and $\left.\mathrm{b}\right)$, in the high frictional velocity regime $\left(u_{*}>0.20 \mathrm{~m} \mathrm{~s}^{-1}\right)$, sensible and latent heat fluxes show moderate to good correlation with frictional velocity $(R=0.65$ for sensible heat flux and $R=0.76$ for latent heat flux). However, in the low frictional velocity regime $\left(u_{*}<0.20 \mathrm{~m} \mathrm{~s}^{-1}\right)$, these fluxes appear to be nearly constant $(H=-7.3 \pm 6.3$ and $\mathrm{LE}=27.9 \pm$ 28.3). The linear increase of sensible and latent heat fluxes with frictional velocity are best fitted with the equation $H=264.9 u_{*}-76.4$ and $\mathrm{LE}=1210 u_{*}-235$, respectively. The $p$-values for these relations were $<0.0001$ and they indicate that the relation is highly statistically significant. Under the stable regime, sensible heat flux $(-15.2$ $\pm 8.2, N=128)$ and latent heat flux (52.4 \pm 41.0 , $N=128)$ were observed to be nearly constant (figure $7 \mathrm{c}, \mathrm{d}$ ). Under the unstable regime, the variation of sensible heat flux with the stability is best fitted as $H=-49.3 \zeta+27(R=-0.47)$ and this relation is highly statistically significant, as

Table 3. The observed mean of the turbulent parameters with respect to variable stability range.

\begin{tabular}{|c|c|c|c|c|c|c|c|c|}
\hline$\zeta$ range & $\zeta$ & $u_{*}\left(\mathrm{~m} \mathrm{~s}^{-1}\right)$ & $w\left(\mathrm{~m} \mathrm{~s}^{-1}\right)$ & $H\left(\mathrm{~W} \mathrm{~m}^{-2}\right)$ & $L E\left(\mathrm{~W} \mathrm{~m}^{-2}\right)$ & $C_{D}$ & $U\left(\mathrm{~m} \mathrm{~s}^{-1}\right)$ & $N$ \\
\hline 5.00 to 18.00 & 11.0 & 0.05 & $+7.40 \times 10^{-17}$ & -3.0 & 10.7 & 0.0101 & 0.79 & 9 \\
\hline 2.76 to 5.00 & 3.6 & 0.09 & $+4.18 \times 10^{-17}$ & -5.6 & 21.1 & 0.0082 & 1.05 & 6 \\
\hline 2.26 to 2.75 & 2.5 & 0.11 & $+1.07 \times 10^{-16}$ & -6.1 & -0.9 & 0.0083 & 1.25 & 2 \\
\hline 1.76 to 2.25 & 2.0 & 0.16 & $+1.55 \times 10^{-16}$ & -14.0 & 49.8 & 0.0112 & 1.59 & 6 \\
\hline 1.26 to 1.75 & 1.6 & 0.20 & $+1.44 \times 10^{-16}$ & -18.2 & 57.0 & 0.0107 & 1.91 & 6 \\
\hline 0.76 to 1.25 & 0.9 & 0.22 & $+1.50 \times 10^{-16}$ & -16.1 & 48.7 & 0.0094 & 2.32 & 30 \\
\hline 0.26 to 0.75 & 0.5 & 0.29 & $+2.61 \times 10^{-16}$ & -17.1 & 53.3 & 0.0119 & 2.70 & 54 \\
\hline 0 to 0.25 & 0.2 & 0.38 & $+2.12 \times 10^{-16}$ & -17.7 & 95.0 & 0.0147 & 3.17 & 16 \\
\hline-0.05 to 0.05 & 0 & 0.35 & $-3.88 \times 10^{-16}$ & 0.6 & 210.1 & 0.0123 & 3.20 & 9 \\
\hline-0.06 to -0.25 & -0.1 & 0.40 & $+1.28 \times 10^{-16}$ & 21.0 & 244.6 & 0.0119 & 3.70 & 24 \\
\hline-0.26 to -0.75 & -0.5 & 0.42 & $+7.93 \times 10^{-17}$ & 58.6 & 325.5 & 0.0116 & 3.91 & 55 \\
\hline-0.76 to -1.25 & -0.9 & 0.34 & $+4.25 \times 10^{-16}$ & 59.0 & 283.0 & 0.0075 & 3.92 & 11 \\
\hline-1.26 to -1.75 & -1.4 & 0.31 & $+3.40 \times 10^{-16}$ & 71.4 & 356.3 & 0.0066 & 3.86 & 2 \\
\hline
\end{tabular}

Note: $\zeta$ is the $z / L$, where $z$ is the observational height and $L$ the Monin-Obukhov length, $u_{*}$ is the frictional velocity, $w$ is the vertical velocity, $H$ is the sensible heat flux, $L E$ is the latent heat flux, $C_{D}$ is the drag coefficient, $U$ is the wind speed, and $N$ is the number of samples. 

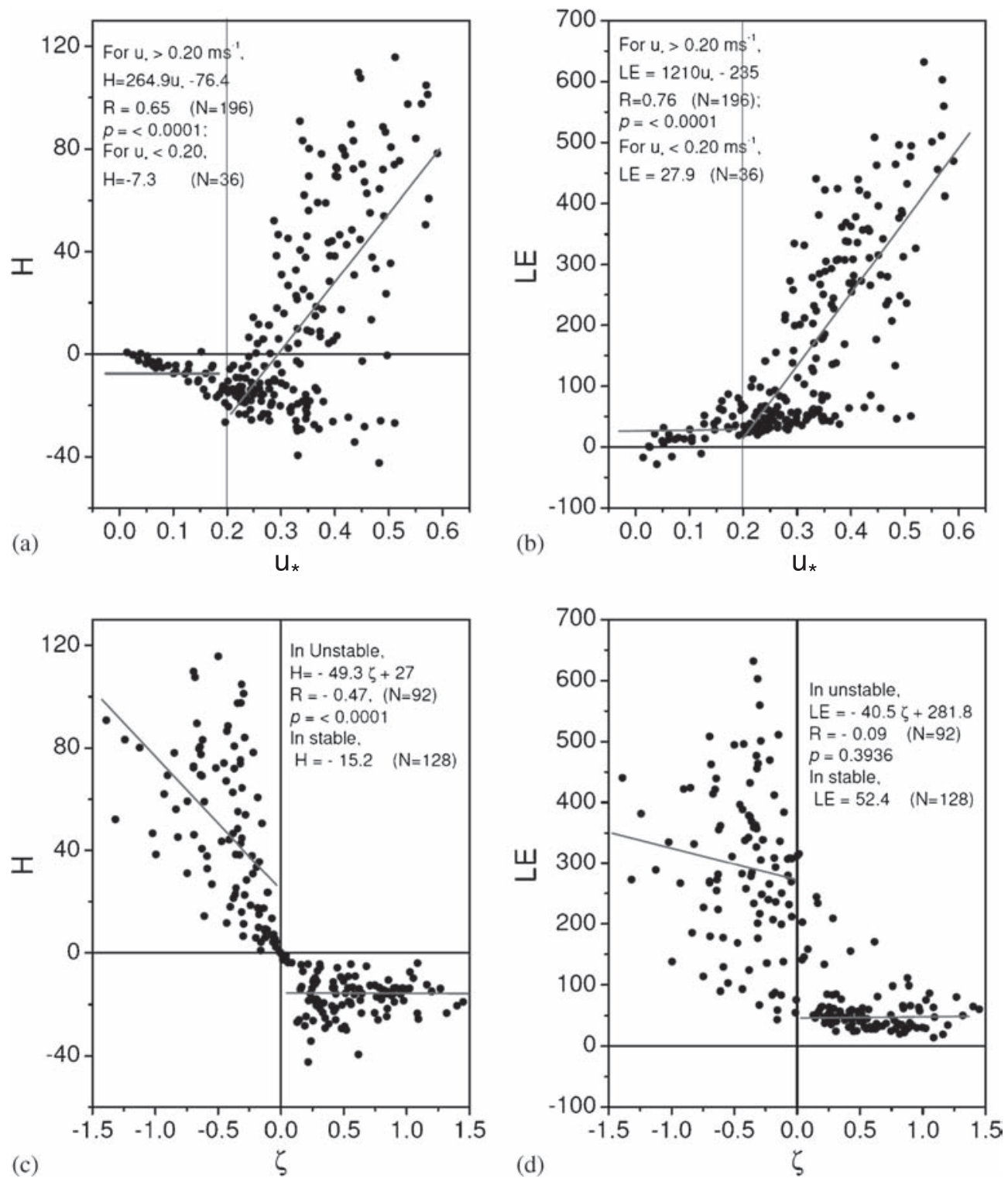

Figure 7. Variation of (a) sensible heat flux, (b) latent heat flux with the frictional velocity and variation, (c) sensible heat flux and (d) latent heat flux with the stability.

$p$-value is $<0.0001$. However, latent heat flux relation with $\zeta$ magnitude under unstable conditions was scattered at $p=0.3936$.

Figure $8(\mathrm{a}, \mathrm{b}$ and $\mathrm{c})$ shows the variation of $C_{D}$, frictional velocity and stability with the mean wind speeds, respectively. These parameters were averaged for wind speed intervals as shown in table 2 . A representative linear relationship of frictional velocity $\left(u_{*}\right)$ with wind speed $(U)$ was found to be $u_{*}=0.11 U-0.01$. Over the Indian subcontinent, a large variability in estimating the surface turbulent heat fluxes by various land surface models were observed (Patil et al. 2011; Panda and Sharan 2012), mainly due to improper representation of soil hydrology-related parameters. In the present study, under stable as well as unstable conditions and under low as well as moderate wind speed conditions, frictional velocity shows a noticeable relationship with wind speed. On the other hand, $C_{D}$ does not show functional dependency with wind speed. In the numerical weather prediction models, where simulation of heat fluxes is carried out by the wind-based $C_{D}$, it may be more appropriate to use frictional velocity and wind speed relations to derive a $C_{D}\left(C_{D}=u_{*}^{2} / U^{2}\right)$ and compute the fluxes with the bulk aerodynamic method. This may improve the representation of surface heat fluxes in the model, and forecast can be improved.

\subsection{Frictional velocity and roughness length with the wind direction}

The $C_{D}$ and roughness length $\left(Z_{O}\right)$ are important parameters needed to define the state of wind. In this case, we derived $Z_{O}$ by a curve-fit method. Figure 9(a) shows a half-hourly diurnal variation 

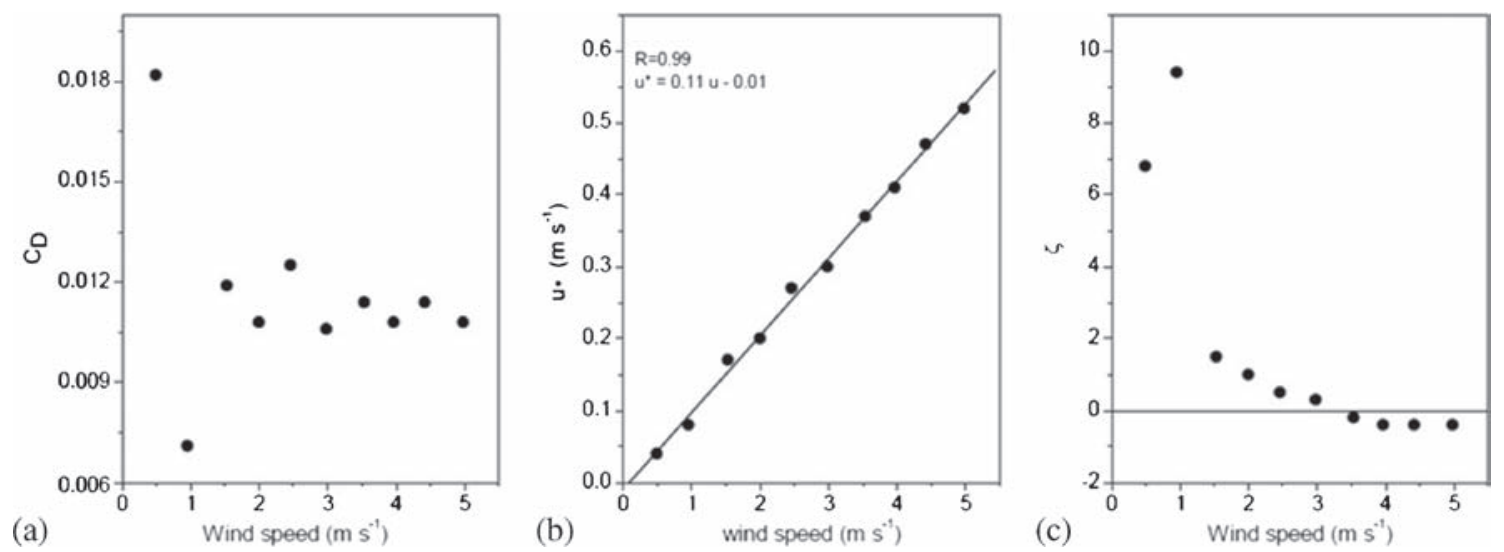

Figure 8. Variation of (a) mean drag coefficient, $C_{D}$ (b) mean frictional velocity, $u_{*}$, and (c) stability, $\zeta$ with mean wind speed.

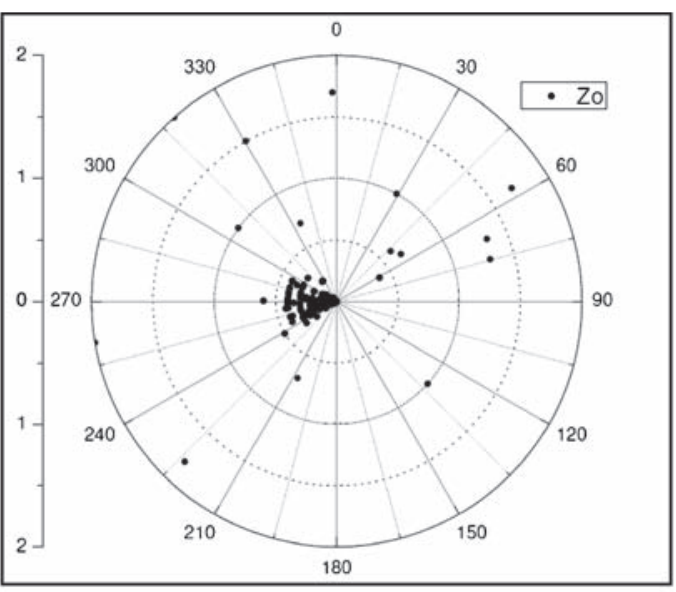

(a)

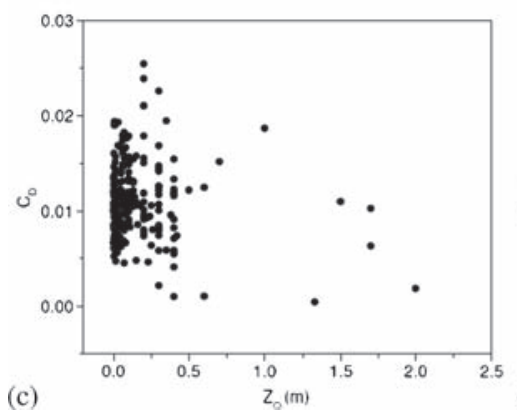

(b)

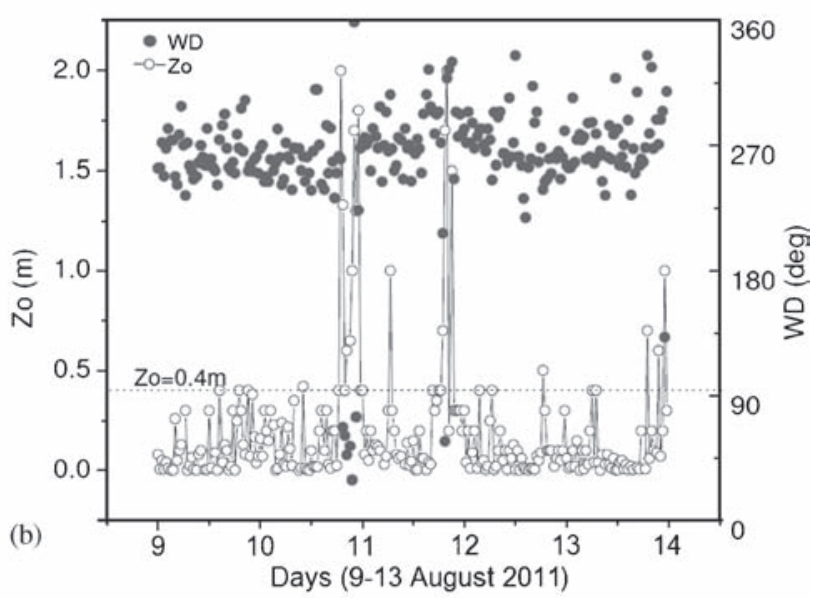

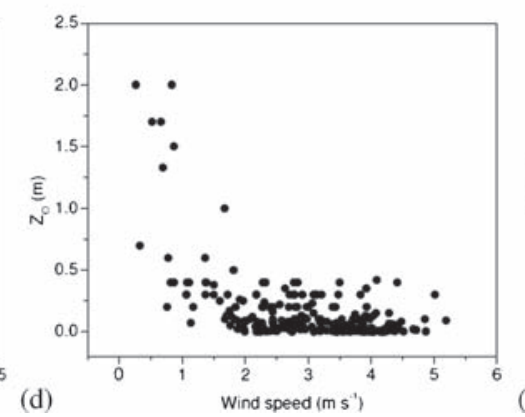

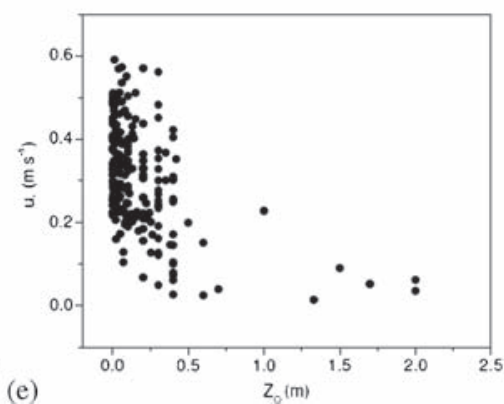

Figure 9. The observed (a) $Z_{O}$ in different wind sectors, (b) half hourly variations of $Z_{O}$ and wind direction, WD during 9-13 August 2011, (c) $C_{D}$ variation with $Z_{O}$, (d) $Z_{O}$ variation with wind speed and (e) $u_{*}$ variation with $Z_{O}$.

of the wind direction as well as $Z_{O}$ for the period 9-13 August, 2011. On few occasions, it is seen that the wind direction changed drastically and during this change, $Z_{O}$ increased 3-4 times. Figure 9 (b) shows the observations of $Z_{O}$ from different wind sectors. During the observational period, the winds were from the sector of 210 300 degree under the influence of Indian summer south-west monsoon. The minimum roughness was observed to be in the sector of 210-300 degree, i.e., from SW to NW direction. Figure 9(c) shows the variation of $C_{D}$ with respect to $Z_{O}$. We did not find a reliable relation between $C_{D}$ and $Z_{O}$. For the observed $Z_{O}, C_{D}$ was in the range of $0.015-0.020$. The $Z_{O}$ variation with wind speed (figure $9 \mathrm{~d}$ ) suggests that $Z_{O}$ depicts higher magnitude $(>1 \mathrm{~m})$ in low wind speed regime $\left(<2 \mathrm{~m} \mathrm{~s}^{-1}\right)$ and for the moderate winds, $Z_{O}$ remained in the range of few $\mathrm{mm}$ to $0.5 \mathrm{~m}$. Similarly, frictional velocity does not depict conclusive relationship with $Z_{O}$ (figure $9 \mathrm{e}$ ). In an earlier study (Patil 2006), over the homogeneous terrain, $C_{D}$ and $Z_{O}$ were also greater in low winds, 
however, over the heterogeneous terrain $C_{D}$ and $Z_{O}$ show large variation (Miao and Ji 1996). Claus et al. (2012) observed that $C_{D}$ and the $Z_{O}$ were highly dependent on wind direction. Thus, the varying nature and structure of land-surface produce different fluxes of momentum, water vapour, and heat due to variation in soil moisture, surface temperature, vegetation, as well as hill slopes ( $\mathrm{Li}$ and Avissar 1994).

\section{Summary and conclusions}

Eddy-covariance systems were used to measure the fluxes of heat and momentum over the Mahabubnagar station and the surface turbulent fluxes of heat, drag coefficient and roughness length were estimated to investigate its relationship with wind speed and atmospheric stability. $C_{D}$, which is necessary for the computation of fluxes by the bulk aerodynamic method, does not show a systematic linear relationship with wind speed. Further, the observations and analysis show the following:

- The stability regime is well depicted by the magnitude of wind speed. In low wind speeds $\left(<2 \mathrm{~m} \mathrm{~s}^{-1}\right)$, the surface layer was stable, whereas, for higher wind speeds $\left(4-6 \mathrm{~m} \mathrm{~s}^{-1}\right)$, the surface layer was unstable.

- The frictional velocity exhibited a strong correlation with wind speed. In low wind speed conditions, frictional velocity is highly correlated with wind speed than that of moderate wind speed conditions.

- In near neutral conditions $(\zeta=0)$, the mean sensible heat flux approaches to $\sim 0 \mathrm{Wm}^{-2}$, but the latent heat flux was observed to be $\sim 200 \mathrm{Wm}^{-2}$. The latent heat was always in an upward direction (+ve), under all stability conditions.

- $Z_{O}$ depicts higher magnitude in low wind speed regime, and for the moderate winds, $Z_{O}$ remained in the range of few $\mathrm{mm}$ to $0.5 \mathrm{~m}$.

\section{Acknowledgements}

The authors express their gratitude to Dr M Rajeevan, Director, Indian Institute of Tropical Meteorology, Pune for inspiration. The CAIPEEX-IGOC program was fully funded by the Ministry of Earth Sciences, Govt. of India.

\section{References}

Agarwal P, Yadav A K, Gulati A, Raman S, Rao S, Singh M P, Nigam S and Reddy N 1995 Surface layer turbulence processes in low wind speeds over land; Atmos. Environ. 29 2089-2098.
Chowdhuri S, Prabha T V, Karipot A, Dharamraj T and Patil M N 2015 Relationship between the momentum and scalar fluxes close to the ground during the Indian post-monsoon period; Bound.-Layer Meteorol. 154 $333-348$.

Clark C A and Arritt R W 1995 Numerical simulations of the effect of soil moisture and vegetation cover on the development of deep convection; J. Appl. Meteorol. 34 2029-2045.

Claus J, Krogstad P-A and Castro Ian P 2012 Some measurements of surface drag in urban-type boundary layers at various wind angles; Bound.-Layer Meteorol. 145 407-422.

Enriquez A G and Friehe C A 1997 Bulk parameterization of momentum, heat and moisture fluxes over a coastal upwelling area; J. Geophys. Res. 102(C3) 5781-5798.

Foken T and Wichura B 1996 Tools for quality assessment of surface-based flux measurements; Agri. Forest Meteorol. 78 83-105.

Garratt J R 1977 Review of drag coefficients over oceans and continents; Mon. Wea. Rev. 105 915-929.

Gillies J A, Nickling W G and King J 2002 Drag coefficient and plant form response to wind speed in three plant species: Burning Bush (Euonymus alatus), Colorado Blue Spruce (Picea pungens glauca.), and Fountain Grass (Pennisetum setaceum); J. Geophys. Res. 107(D24).

Ham J M and Heilman J L 2003 Experimental test of density and energy-balance corrections on carbon dioxide flux as measured using open-path eddy covariance; Agron. J. 95 1393-1403.

Krishnan P and Kunhikrishnan P K 2002 Some characteristics of atmospheric surface layer over a tropical inland region during southwest monsoon period; Atmos. Res. 62 $111-124$.

Kulkarni J R et al. 2012 Cloud Aerosol Interaction and Precipitation Enhancement Experiment (CAIPEEX): Overview and preliminary results; Curr. Sci. 102 413-425.

Kusuma G Rao 2004 Estimation of the exchange coefficient of heat during low wind convective conditions; Bound.Layer Meteorol. 111 247-273.

Kusuma G Rao, Narasimha R and Prabhu A 1996 Estimation of drag coefficient at low wind speeds over the monsoon trough land region during MONTBLEX-90; Geophys. Res. Lett. 23 2617-2620.

Lee X and Massman W J 2011 A perspective on Thirty Years of the Webb, Pearman and Leuning density corrections; Bound.-Layer Meteorol. 139 37-59.

Lee X, Massman W and Law B 2004 Handbook of Micrometeorology: A Guide for Surface Flux Measurement and Analysis; Kluwer Academic Publishers, pp. 60-61.

Leuning R and Moncrieff J 1990 Eddy covariance $\mathrm{CO}_{2}$ flux measurements using open- and closed-path analysers: Corrections for analyser water vapour sensitivity and damping fluctuations in air sampling tubes; Bound.-Layer Meteorol. 53 63-76.

Leuning R, Denmead O T and Lang A R G 1982 Effects of heat and water vapor transport on eddy covariance measurement of $\mathrm{CO}_{2}$ fluxes; Bound.-Layer Meteorol. 23 209-222.

Li B and Avissar R 1994 The impact of spatial variability of land-surface characteristics on land surface heat-fluxes; J. Climate 7 527-537.

Liebethal C and Foken T 2003 On the significance of the Webb correction to fluxes; Bound-Layer Meteorol. 109 99-106.

Liebethal C and Foken T 2004 On the significance of the Webb correction to fluxes: Corrigendum; Bound.-Layer Meteorol. 113301. 
Mahrt L, Vickers D, Sun J, Jensen N O, Jorgensen H, Pardyjak E and Fernando H 2001 Determination of the surface drag coefficient; Bound.-Layer Meteorol. 99 249-276.

Mahrt L, Sun J and Stauffer D 2015 Dependence of turbulent velocities on wind speed and stratification; Bound.-Layer Meteorol. 155 55-71.

Massman W J 1991 The attenuation of concentration fluctuations in turbulent-flow through a tube; J. Geophys. Res. 96D 15,269-15,273.

Mauder M and Foken T 2006 Impact of post-field data processing on eddy covariance flux estimates and energy balance closure; Meteorologische Z 15 597-609.

Miao M and Ji J 1996 Study on diurnal variation of bulk drag coefficient over different land surfaces; Meteorol. Atmos. Phys. 61(3-4) 217-224.

Miller M J, Beljaars A C M and Palmer T N 1992 The sensitivity of the ECMWF model to the parameterization of evaporation from the tropical oceans; J. Climate $\mathbf{5}$ 418-434.

Panda J and Sharan M 2012 Influence of land-surface and turbulent parameterization schemes on regionalscale boundary layer characteristics over northern India; Atmos. Res. 112 89-111.

Patil M N 2006 Aerodynamic drag coefficient and roughness length for three seasons over a tropical western Indian station; Atmos. Res. 80 280-293.

Patil M N, Waghmare R T, Halder S and Dharmaraj T 2011 Performance of Noah land surface model over the tropical semi-arid conditions in western India; Atmos. Res. 99 $85-96$.
Patil M N, Dharmaraj T, Waghmare R T, Prabha T V and Kulkarni J R 2014 Measurements of carbon dioxide and heat fluxes during monsoon-2011 season over rural site of India by eddy covariance technique; J. Earth Syst. Sci. $123177-185$.

Segal M and Arritt R W 1992 Non-classical mesoscale circulations caused by surface sensible heat flux gradients; Bull. Am. Meteorol. Soc. 73 1593-1604.

Suzuki N, Toba Y, Komori S, Takagaki N, Baba Y, Kubo T, Shintaku K and Yamamoto M 2014 Variation of the drag coefficient investigated by using tower-based long period measurements - condition of high wind speed with following and cross swell; Int. J. Offshore and Polar Engg. 24(3) 168-173.

Webb E K, Pearman G I and Leuning R 1980 Correction of the flux measurements for density effects due to heat and water vapour transfer; Quart. J. Roy. Meteorol. Soc. 106 $85-100$.

Wen F, Gao Z, Wu Z and Lu H 2005 Wind speed scaling and the drag coefficient; Acta Oceanol. Sin. 24(4) 29-42.

Xiao W, Liu S, Wang W, Yang D, Xu J, Cao C, Li H and Lee X 2013 Transfer coefficients of momentum, heat and water vapour in the atmospheric surface layer of a large freshwater lake; Bound.-Layer Meteorol. 148 479-494.

Zachry B C, Schroeder J L, Kennedy A B, Westerink J J and Letchford C W 2013 A case study of nearshore drag coefficient behavior during hurricane Ike (2008); J. Appl. Meteorol. Climatol. 52 2139-2146.

Zhu P and Furst J 2013 On the parameterization of surface momentum transport via drag coefficient in low-wind conditions; Geophys. Res. Lett. 40 2824-2828. 